\title{
Posterior instrumentation for unstable thoracolumbar
} fractures

\section{Pandey BK', Pradhan RL²}

${ }^{1}$ Bimal Kumar Pandey, Assistant Professor; ${ }^{2}$ Rabindra Lal Pradhan, Professor; Department of Orthopaedics, Kathmandu Medical College Teaching Hospital, Kathmandu, Nepal

\begin{abstract}
Background: About 90 percent of all spinal injuries involve the thoracolumbar region. Unstable fractures need surgical treatment to achieve a painless, balanced and stable spine preserving or recovering neurological function, highest degree of spinal motion and to allow early patient mobilization.

Objective: This study was carried out to evaluate radiological outcome of posterior instrumentation in thoracolumbar fractures.

Methodology: A total of 110 patients with thoracolumbar fracture were included in the study, which was carried out at Kathmandu Medical College Teaching Hospital from December 2011 to December 2016. Unstable Arbeitsgemeinschaft fur Osteosynthesefragen type A and type B fractures were treated with short segment instrumentation and type $C$ with long segment instrumentation. Radiological evaluation of postoperative correction of kyphotic angle and vertebral height was measured and was compared with immediate postoperative correction and loss of correction in two years final follow up.

Results: Mean postoperative correction of vertebral kyphotic angle was $25^{\circ}$ and loss of correction in final follow up was $5^{\circ}$. Mean postoperative vertebral height correction was $24 \%$ and its loss in final follow up was $2 \%$. There was no significant difference in loss of correction of vertebral kyphosis and vertebral height in short segment and long segment fixation in final follow up.

Conclusion: Long segment posterior instrumentation results in good reduction and its maintenance for Arbeitsgemeinschaft fur Osteosynthesefragen type $C$ thoracolumbar fractures whereas similar results can be achieved with short segment posterior instrumentation in type $A$ and type $B$ fractures.
\end{abstract}

Key words: Posterior instrumentation, Spine, Thoracolumbar, Unstable fractures

\section{INTRODUCTION}

bout 90 percent of all spinal injuries involve thoracolumbar region ${ }^{1,2}$. Various methods of treatment have been advocated ${ }^{3}$. There had been controversies between operative and non operative approaches ${ }^{2-4}$. Mostly stable fractures are treated nonsurgically and unstable fractures are treated surgically 3,5 . Regarding burst fracture there has always been debate between operative and conservative methods of treatment ${ }^{1,6-8}$. Surgical treatment can be either anterior or posterior or combined anterior and posterior $^{2,9,10}$. Posterior fixation with pedicle screw

Address for correspondence

Bimal Kumar Pandey

Assistant Professor

Department of Orthopaedics

Kathmandu Medical College Teaching Hospital

Kathmandu, Nepal

E-mail: bimalpandey@hotmail.com fixation gives three-column fixation and is considered as most stable construct. Posterior instrumentation can be of mono segmental, short segmental or long segmental and can also be with or without fusion ${ }^{11,12}$. Highly unstable fractures need long segmental fixation whereas lesser unstable fractures can be stabilized with short segmental instrumentation ${ }^{13}$. Always there remained controversies regarding level of instrumentation. Long segmental fixation gives good stability but reduces motion segments whereas short segmental fixation is less stable but preserves motion segments $s^{4,5,14}$. This study was carried out to evaluate radiological outcome of posterior instruments in thoracolumbar fractures.

\section{METHODOLOGY}

This is a prospective cohort study carried out at Kathmandu Medical College Teaching Hospital from December 2011 to December 2016. Ethical clearance was achieved from the hospital ethical committee. 
Total of 110 patients with thoracolumbar fracture with or without neurological involvement and with at least two years of follow up were included in the study. Indication of surgery was decided by Thoracolumbar injury Classification and Severity Score (TLICS) $)^{15}$ and morphology of fracture was classified with $\mathrm{AO}$ (Arbeitsgemeinschaft fur Osteosynthesefragen) classification ${ }^{16}$. Fractures up to AO A 3.1 were excluded as they were treated conservatively.

Under general anesthesia patients were placed on operation table in prone position with two transverse rolls under the chest and pelvis. By securing this position spine becomes hyperextended and reduction can be achieved to some extent. Abdomen remains free to decrease intra-abdominal pressure. A standard midline posterior incision was used centering the injured vertebra. Sub periosteal dissection was done to expose all the posterior elements up to the tip of transverse process. Entry point for pedicle screw insertion was then identified. In the thoracic vertebra the point was identified lateral to a vertical line bisecting the facet joint along the upper one third of the transverse process. For lumbar vertebra same point was identified along the lateral aspect of the facet joint, where they intersect a line passing through the middle portion of the transverse process. Pedicle probe was inserted to cannulate the pedicle with C-arm control in lateral view. The tract was checked for pedicle breach with pedicle sound. Screw diameter was estimated by measuring pedicle diameter in axial CT scan. Pedicle screws were inserted in fractured vertebra also if pedicles were found intact in CT scan. After insertion of screws, the rods were contoured to the normal sagittal curvature of the spine to achieve adequate reduction. Rods were first inserted in proximal screws and then pushed into distal screws. By doing this maneuver angular deformity was corrected to some extent. Distraction between proximal and distal screws was done to restore vertebral height and to decompress the spinal canal withligamentotaxis. AO type A and type B fractures were treated with short segment instrumentation (one vertebra above and one vertebra below the fracture) (Figure 1a-1c). Type $C$ fractures were treated with long segment instrumentation (two vertebrae above and two vertebrae below the fracture)(Figure 2a-2d). In short segment instrumentation pedicle screws were inserted in fracture vertebra if pedicles were intact. In those cases where pedicle screws were not inserted cross-link was attached between two rods to increase strength of the implant. In long segment instrumentation cross-link was attached between the rods. Posterior fusion was done in fractures with posterior ligamentous complex disruption.
Bone graft was taken from the spinous process of vertebrae to be fused. Patients were ambulated with brace for about three months postoperative. Follow up $\mathrm{X}$-rays were done in six weeks, three months, six months, one year and two years. Kyphotic angle was measured as the angle between the parallel lines of upper margin and lower margin of the vertebral body in lateral view of X-ray of spine. Its immediate postoperative correction and loss of correction in final follow upwere compared. Vertebral height reduction was measured by percentage of the posterior body height of fractured vertebra with average posterior height of body of immediate upper and lower vertebrae. Percentage of vertebral body height reduction, its postoperative correction and its loss in final follow up were compared. Complications were recorded. Statistical analysis was performed with SPSS (Chicago, Illinois, USA) version 15 software for windows. Student's t-test was used for statistical analysis to determine significance. P-value of 0.05 or less was considered significant.

\section{RESULTS}

The total number of cases operated in this period was 185. One hundred and ten patients, who came for follow up for two years were included in this study. Among them there were 72 males and 38 females. The mean age of the patients was 38.4 (18-54) years. L1 fracture was found in 35 (31.81\%) of the patients, D12 in 31 (28.18\%), L2 in 18 (16.36), D11 in 8 (7.27\%), D10 in 5 (4.54\%) and rest of the dorso-lumbar fracture was in $13(11.81 \%)$ of patients. There were $56 \mathrm{AO}$ type A patients, 31 type B and 23 type $C$. Mean (standard deviation) preoperative kyphotic angle was $25^{\circ}( \pm 8.5)$ and immediate post operative was $6^{\circ}( \pm 3.2)$. Mean postoperative correction in kyphotic angle was $19^{\circ}$. Mean kyphotic angle in final follow was $11^{\circ}( \pm 2.4)$. Loss of kyphotic correction in final follow up was $5^{\circ}( \pm 4.2)$. Preoperative average vertebral height reduction was $29 \%( \pm 9.3)$ and was $5 \%$ $( \pm 4.2)$ postoperatively. Mean postoperative correction of vertebral height was of $24 \%$. Mean vertebral height reduction in final follow up was $7 \%( \pm 5.3)$. Hence loss of vertebral height correction was $2 \%$. Kyphotic angle correction and vertebral height restoration was better in postoperative period. Though there was loss of kyphotic angle correction and loss of vertebral height correction in final follow up, they were not statistically significant. Among AO type A and B fractures, where short segment fixation was done, post operative kyphotic angle correction was of $28^{\circ}( \pm 7.3)$ and among AO type $C$ fractures, where long segment fixation was done, it was $16^{\circ}( \pm 8.5)$. Loss of kyphotic angle correction in final follow up in short segment fixation group was $6^{\circ}( \pm 3.5)$ 
and in long segment fixation group it was $4^{\circ}( \pm 2.2)$. There was no statistically significant difference of these parameters in short segment and long segment fixation groups. Post-operative increase in vertebral height was $18 \%$ and $24 \%$ in long segment and short segment fixation respectively. Loss of vertebral height correction in both the groups was $2 \%$ and $3 \%$ respectively. These parameters were not significantly different. There was no significant difference in final radiological outcome among the patients with intermediate pedicle screw in fracture vertebra and patients with cross link group. Posterior fusion with bone graft was done in 45 patients. There was no significant difference between the results in fusion and non fusion group in mean postoperative kyphotic angle correction and loss of correction in final follow up. Similarly there was no difference in mean immediate postoperative height correction and in final follow up in these two groups (Table 1).

Postoperative wound infection was found in seven patients (6.3\%). Superficial wound infection healed with regular dressing and appropriate antibiotic. Deep infection needed debridement and sensitive antibiotics for the control of infection (Table 2). Finally wound healed without removing the implants. Implant failure was found in seven $(6.3 \%)$ patients. One patient $(0.9 \%)$ had postoperative cauda equina syndrome, which recovered subsequently. Bladder and bowel function recovered, however there was mild motor weakness in one lower limb at the end of two years follow up.

\section{DISCUSSION}

About 50 to $88 \%$ of spine fractures occur at the dorsolumber junction ${ }^{7,8,13}$. In our study $92(83.63 \%)$ of the fracture were in dorso-lumbar junction (D11-L2). The treatment of thoracolumbar fracture remains challenging and debatable. Posterior instrumentation with pedicle screw fixation provided sufficient stability ${ }^{5,13,18-21,23,24}$. Payer ${ }^{7}$ reported loss of kyphosis correction of $3^{\circ}$ with no implant failure in treatment of unstable thoracolumbar fractures using posterior instrumentation with anterior support. Been et al. ${ }^{17}$ conducted comparison of combined anterior and posterior stabilization versus posterior instrumentation only for thoracolumbar burst fractures and found loss of reduction greater than $5^{\circ}$ and instrumentation failure significantly more in posterior instrumentation only group, but the kyphosis angle at late follow-up (average of 6 years) did not differ between the groups. In our study immediate post-operative kyphosis correction was $19^{\circ}$ and loss of correction in final follow up was $5^{\circ}$. There was $24 \%$ of immediate postoperative correction of vertebral height with $2 \%$ of loss of correction in final follow up.

\section{Table 1: Comparison between fusion and non-fusion cases}

\begin{tabular}{|c|c|c|c|}
\hline & $\begin{array}{l}\text { Fusion group } \\
\qquad(\mathrm{N}=45)\end{array}$ & $\begin{array}{l}\text { non-fusion group } \\
\qquad(\mathrm{N}=65)\end{array}$ & $\mathbf{p}$ \\
\hline $\begin{array}{l}\text { Mean post-operative kyphotic angle correction } \\
\text { Degree (SD) }\end{array}$ & $21(4.5)$ & $23(5.2)$ & 0.61 \\
\hline $\begin{array}{l}\text { Mean loss of kyphotic angle correction in final follow up } \\
\text { Degree (SD) }\end{array}$ & $4(2.6)$ & $5(3.1)$ & 0.74 \\
\hline $\begin{array}{l}\text { Mean post-operative increase in vertebral height } \\
\text { Percentage (SD) }\end{array}$ & $19(2.5)$ & $21(3.2)$ & 0.81 \\
\hline $\begin{array}{l}\text { Mean loss of vertebral height correction in final follow up } \\
\text { Percentage (SD) }\end{array}$ & $3(2.5)$ & $3(2.9)$ & 0.71 \\
\hline
\end{tabular}

$\mathrm{SD}=$ standard deviation

\section{Table 2: Complications}

\begin{tabular}{lcc}
\hline \multicolumn{1}{c}{ Complications } & Number (\%) & Remarks \\
\hline Wound infection & $7(6.3 \%)$ & Healed with wound dressings \\
Deep & $2(1.8 \%)$ & $5(4.5 \%)$ \\
Superficial & $7(6.3 \%)$ & Fusion - 1 \\
Implant failure & $2(1.8 \%)$ & Non fusion - 6 \\
Screw breakage & $2(1.8 \%)$ \\
Rod breakage & $3(2.7 \%)$ & $1(0.9 \%)$ \\
Cap failure & & \\
\hline Post-operative cauda equina & & \\
\hline
\end{tabular}




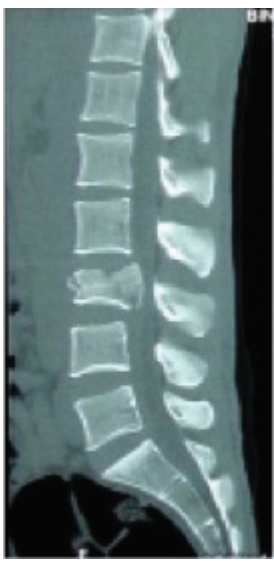

1 a.

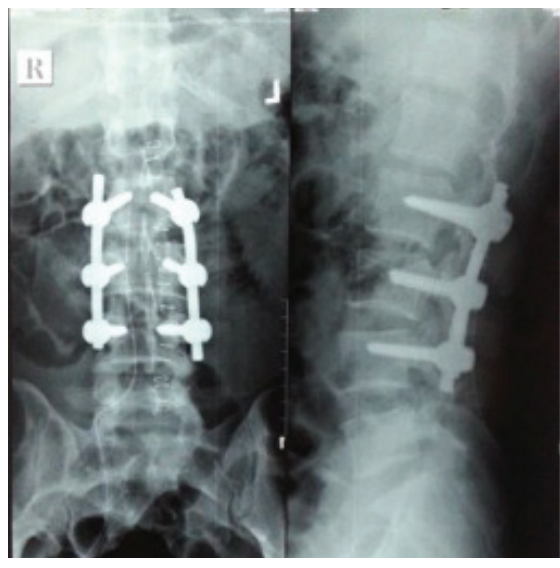

$1 b$.

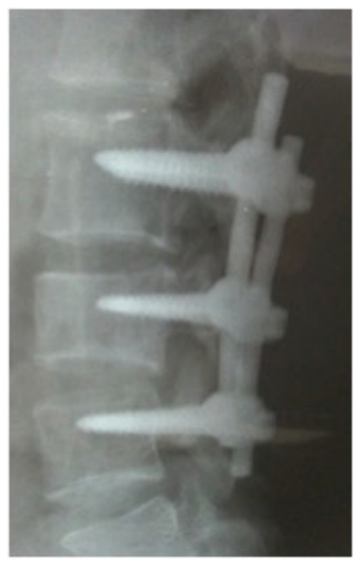

1c.

Figure 1a: Pre-operative $C T$ image of burst fracture of $L 3$ vertebra

Figure $1 \mathrm{~b}$ :X-ray of Lumbar Spine in post-operative period

Figure 1c: X-ray in final follow up

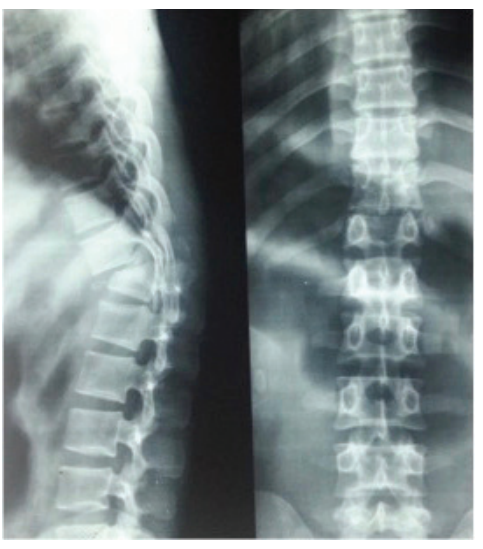

$2 \mathrm{a}$.

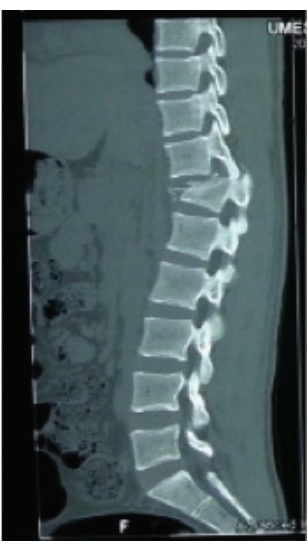

$2 b$.

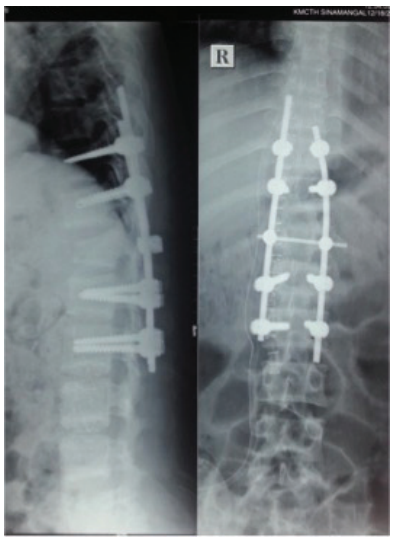

$2 c$.

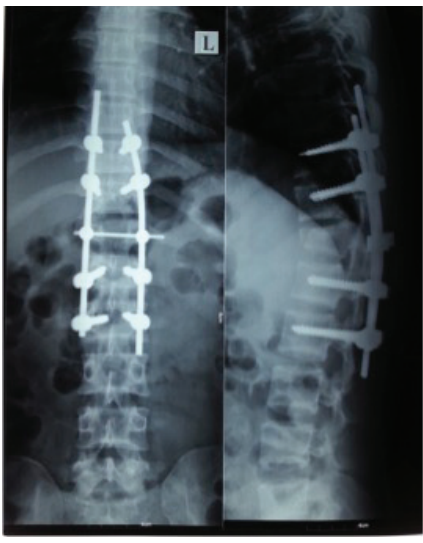

2d.

Figure 2a: Pre-operative $X$-ray of fracture dislocation of D12 vertebra (AO type C)

Figure $\mathbf{2 b}$ : Pre-operative CT scan

Figure 2c: Post-operative X-ray

Figure 2d:X-ray in final follow up

Regarding posterior instrumentation there are options of long segmental and short segment fixation. Short segment posterior instrumentation preserves motion segments whereas long segment fixation gives more stability $5,13,18,19,20,21$. Butt et al. ${ }^{13}$ in their study found $3.46^{\circ}$ of loss of kyphosis correction and $3 \%$ loss of vertebral height in final follow-up with short segment fixation. We found $6^{\circ}$ of loss of kyphotic angle correction in final follow in short segment fixation with three percent of loss of vertebral height correction. In our study short segment fixation was done only in unstable burst fracture and flexion distraction injuries. Regarding long segment fixation we found four degree loss of kyphotic angle correction and two percent of loss of vertebral height restoration in final follow up. Tezeranet al. ${ }^{21}$ showed that long segment group had better outcome at final follow-up. Short segment group had a $55 \%$ failure rate. Scholl et al. ${ }^{22}$ observed posterior instrumentation with two levels above and one level below the fracture vertebra had lower failure rate than one level above and one level below instrumentation. Mahar et al. ${ }^{23}$ and Norton et al. ${ }^{24}$ reported that additional screws in fracture vertebra (intermediate screws) gives better reduction and kyphosis correction. We found no significant difference in radiological final result in the patients where intermediate screw were used. 
We found there was no significant difference in the results of fusion and non fusion cases in terms of kyphotic angle correction and vertebral height maintenance. Fusion always lowers the risk of implant failure ${ }^{25,26}$. Hwang et al. ${ }^{27}$ concluded that implant related complications were less in fusion group. Whereas some studies demonstrated that spinal fusion is not necessary in long segment and short segment posterior instrumentation ${ }^{26,28-30}$. In our study there was seven (6.3\%) implant failure. Six (5.4\%) of them were with non-fusion instrumentation.

We had infection in seven (6.3\%) cases, out of which there were two $(1.8 \%)$ superficial and five $(4.5 \%)$ deep. Two cases with deep infection were treated by debridement and appropriate antibiotic for longer period. Superficial wound infection was treated with regular would dressing and proper antibiotics. Various studies showed post-operative wound infection rate increases up to $25 \%$ in paralytic $\operatorname{cases}^{31-33}$.

\section{CONCLUSION}

Short segment posterior instrumentation results in good reduction in unstable burst and chance fractures and long segment posterior instrumentation results in good reduction in thoracolumbar fracture dislocation.

\section{REFERENCES}

1. Müller U, Berlemann U, Sledge J, Schwarzenbach O. Treatment of thoracolumbar burst fractures without neurologic deficit by indirect reduction and posterior instrumentation: bisegmental stabilization with monosegmental fusion. Eur Spine J. 1999;8:284-9.

2. Alpantaki K, Bano A, Pasku D, Mavrogenis AF, Papagelopoulos PJ, Sapkas GS, et al. Thorocolumbar burst fractures: A systematic review of management. Orthopedics. 2010;33:422-9.

3. Mikles MR, Stchur RP, Graziano GP. Posterior instrumentation for thoracolumbar fractures. J Am AcadOrthop Surg. 2004;12:424-35.

4. Dashti H, Lee HC, Karaikovic EE, Gaines RW Jr. Decision making in thoracolumbar fractures. Neurology India. 2005 December;53(4):534-41.

5. Whang PG, Vaccaro AR. Thoracolumbar fractures: Posterior instrumentation using distraction and ligamentotaxis reduction. J Am AcadOrthop Surg. 2007;15(11):695-701.

6. Wood KB, Buttermann GR, Phukan R, Harrod CC, Mehbod A, Shannon B, et al. Operative compared with nonoperative treatment of a thoracolumbar burst fracture without neurological deficit. J Bone Joint Surg Am. 2015;97:3-9.

7. Payer M. Unstable burst fractures of the thoracolumbarjunction:treatmentby posterior bisegmental correction/fixation and staged anterior corpectomy and titanium cage implantation. ActaNeurochir (Wien). 2006;148:299-306.

8. Rajasekaran S, Kanna RM, Shetty AP. Management of thoracolumbar spine trauma: An overview. Indian J Orthop. 2015 Jan-Feb;49(1):72-82.

9. Oprel PP, Tuinebreijer WE, Patka P, Hartog Dd. Combined anterior-posterio surgery versus posterior surgery for thoracolumbar burst fractures:
A systematic review of the literature. The Open Orthopaedic Journal. 2010;4:93-100.

10. Defino HLA, Rodriguez-Fuentes AE. Treatment of fractures of the thoracolumbar spine by combined anteroposterior fixation using the Harms method. Eur Spine J. 1998;7:187-94.

11. Sargin S, Ucar BY, Necmioglu S, Bulut M, Gem M. Clinical and radiological results of posterior instrumentation without fusion for thoracolumbar fractures. Afr. J. Pharmacol. 2011;5(7):819-822.

12. Tian NF, Wu YS,Zhang XL, Wu XL, Chi YL, Mao FM. Fusion versus Nonfusion for surgically treated thoracolumbar burst fractures: A meta-analysis. (Cited 2016 July 19). Available from: https://doi. org/10.1371/journal.pone.0063995.

13. Butt MF, Farooq M, Mir B, Dhar AS, Hussain A, Mumtaz M. Management of unstable spinal injuries by posterior short segment spinal fixation. International Orthopaedics (SICOT). 2007;31: 259264.

14. Peters T, Chinthakunta SR, Hussai M, Khalil S. Pedicle screw configuration for thoracolumbar burst fracture treatment: short versus long posterior fixation constructs with and without anterior column augmentation. Asian Spine Journal. 2014;8(1):35-43.

15. Lee JY, Vaccaro AR, Lim MR, Öner FC, Hulbert RJ, Hedlung $\mathrm{R}$, et al. Thoracolumbar injury classification and severity score: a new paradigm for the treatment of thoracolumbar spine trauma. J Orthop Sci. 2005;10:671-75.

16. Magerl F, Aebi M, Gertzbein SD, Harms J, Nazarian S. A comprehensive classification of thoracic and lumbar injuries. Eur Spine J. 1994;3:184-201.

17. Been HD, Bouma GJ. Comparison of two types of surgery for thoraco-lumbar burst fractures: combined anterior and posterior stabilization vs, 
posterior instrumentation only. ActaNeurochi (Wien). 1999;141(4):349-57.

18. Hitchon PW, Torner J, Eicholz KM. Comparison of anterolateral and posterior approaches in the management of thoracolumbar burst fractures. J Neurosurg Spine. 2006;5(2):117-25.

19. Glaser JA, Estes WJ. Distal short segment fixation of thoracolumbar and lumbar injuries. lowa Orthop J. 1998;18:87-90.

20. Wang ST, Goel VK, Fu CY, Kubo S, Choi W, Liu CL, et al. Comparison of two interbody fusion cages for posterior lumbar interbody fusion in a cadaveric model. International Orthopaedics (SICOT). 2006;30:299-304.

21. Tezeren G, Kurul.Posterior fixation of thoracolumbar burst fracture: short-segment pedicle fixation versus long-segment instrumentation. J Spinal Disord Tech. 2005 Dec;18(6):485-8.

22. Scholl BM, Theiss SM. Kirkpatrick JS. Short segment fixation of thoracolumbar burst fractures. Orthopedics. 2006 Aug;29(8):703-8.

23. Mahar A, Kim C, Wedemeyer M, Mitsunaga L, Odell T, Johnson B, et al. Short-segment fixation of lumbar burst fractures using pedicle fixation at the level of the fracture. Spine. 2007;32(14):1503-07.

24. Norton RP, Milne EL, Kaimrajh DN, Eismont FJ, Latta LL, Williams SK. Biomechanical analysis of four- versus six-screw constructs for shortsegment pedicle screw and rod instrumentation of unstable thoracolumbar fractures. Spine J. 2014 Aug;14(8):1734-9.

25. Qian BP, Qiu Y, Wang B, Yu Y, Zhu ZZ. Effect of posterolateral fusion on thoracolumbar burst fractures. Chin J Traumatol. 2006 Dec;9(6):349-55.

26. Wang ST, Ma HL, Liu CL,YuWk, Chang MC, Chen $\mathrm{TH}$. Is fusion necessary for surgically treated burst fractures of the thoracolumbar and lumbar spine? : A prospective, randomized study. Spine (Phila Pa 1976). 2006 Nov 1;31(23):2646-52.

27. Hwang JH, Modi HN, Yang JH, Kim SJ, Lee SH. Short segment pedicle screw fixation for unstable T11-L2 fractures: with or without fusion? A threeyear follow-up study. ActaOrthop Belg. 2009 Dec;75(6):822-7.

28. Tezeran G, Bulut O, Tukenmez M, Ozturk H, Oztemur $Z$, Ozturk A. Long segment instrumentation of thoracolumbar burst fracture: fusion versus nonfusion. J Back MusculoskeletRehabil. 2009;22(2):107-12.

29. Jindal N, Sankhala SS, Bachhal V. The role of fusion in the management of burst fractures of the thoracolumbar spine treated by short segment pedicle screw fixation: a prospective randomised trial. J Bone Joint Surg Br. 2012 Aug;94(8):1101-6.

30. Dai LY, Jiang LS, Jiang SD. Posterior short-segment fixation with or without fusion for thoracolumbar burst fractures. A five to seven-year prospective randomized study, J Bone Joint Surg Am. 2009 May;91(5):1033-41.

31. Gaines DL, Moe JH, Bocklage J. Management of wound infections following Harrington instrumentation and spine fusion. J Bone Joint Surg Am. 1970; 52:404-5.

32. Wimmer $C$, Gluch $H$, Franzreb $M$, Ogon $M$. Predisposing factors for infection in spine surgery: a survey of 850 spinal procedures. J Spinal Disord. 1998 Apr;11(2):124-8.

33. Aydinli U, Karaeminogullari O, Tiskaya K. Postoperative deep wound infection in instrumented spinal surgery. Acta Orthoaedica Belgica. 1999;65(2):182-7. 